\title{
Analytical and experimental procedures for the realigning of the 26th floor of the "Pirelli" tall building after the airplane crash on April 2002
}

\author{
Alberto FRANCHI \\ Professor \\ Politecnico di Milano \\ Milan, Italy \\ alberto.franchi@polimi.it
}

\author{
Maurizio ACITO \\ Assistant Professor \\ Politecnico di Milano \\ Milan, Italy \\ acito@stru.polimi.it
}

\author{
Pietro CRESPI \\ Post doc. Fellow \\ Politecnico di Milano \\ Milan, Italy \\ pietro.crespi@polimi.it
}

\section{Antonio MIGLIACCI \\ Professor \\ Politecnico di Milano \\ Milan, Italy \\ migliacci@stru.polimi.it}

\section{Summary}

This paper is meant to deliver an overview on the damages and the following repairs of the structures of the $26^{\text {th }}$ and $27^{\text {th }}$ floor due to the plane accident occurred on April, the $18^{\text {th }} 2002$.

An aircraft Commander 112 TC Commander impacted the facade of the Pirelli skyscraper getting into the building, where its gasoline tanks exploded.

This paper is divided into two parts. The first one focuses on a simplified analysis, of the witnessed structural damages, making some necessary assumptions on the dynamic of the accident.

In the second one, the realigning process is presented.

Keywords: realigning process, rigid-plastic, hydraulic jacks, r.c. beams and slab

\section{Premises}

On $18^{\text {th }}$ April 2002, at 17.47 hours, a 112 TC Commander single-engine plane struck the facade of the Pirelli skyscraper overlooking Piazza Duca d'Aosta (Fig. 1) between the deck beams of the $26^{\text {th }}$ floor and those of the $27^{\text {th }}$ floor, near the central cross-section, penetrating inside the building (Fig. 2).

As the result of the collision and the explosion of the two fuel-tanks, located near the wings, the plane's engine was severed from the fuselage, ending up outside the opposite façade that is facing Via Fabio Filzi.

The damage caused to the structures ([1], [2] and [3]) on the $26^{\text {th }}$ floor indicated cracks at mid span of the longitudinal beams as well as at the fixed ends and along the perimeter of the thin r.c. slab above the beams (Fig. 4). That damages result in conspicuous displacements at mid span of the beams, ranging from a maximum of $25 \mathrm{~cm}$ of beam No. 5 to $14 \mathrm{~cm}$ of beam No. 1 (Fig. 3).

As regard to the deck of the $27^{\text {th }}$ floor, the deformation evidenced an upward residual displacement of 5-6 cm at mid span of beam No. 5, the most severely damaged one, confirming the hypothesis that the impulse due to the explosion of the gasoline tanks was the major cause of the permanent displacements.

The problem of the realigning the beams of the $26^{\text {th }}$ deck appeared to be of fundamental importance inasmuch as the mandate from the owner (Public Administration of Lombardia Region) was to attempt to preserve the existing structures. With this in mind, it was essential to force the beams upwards by using hydraulic jacks on a pack prop. 


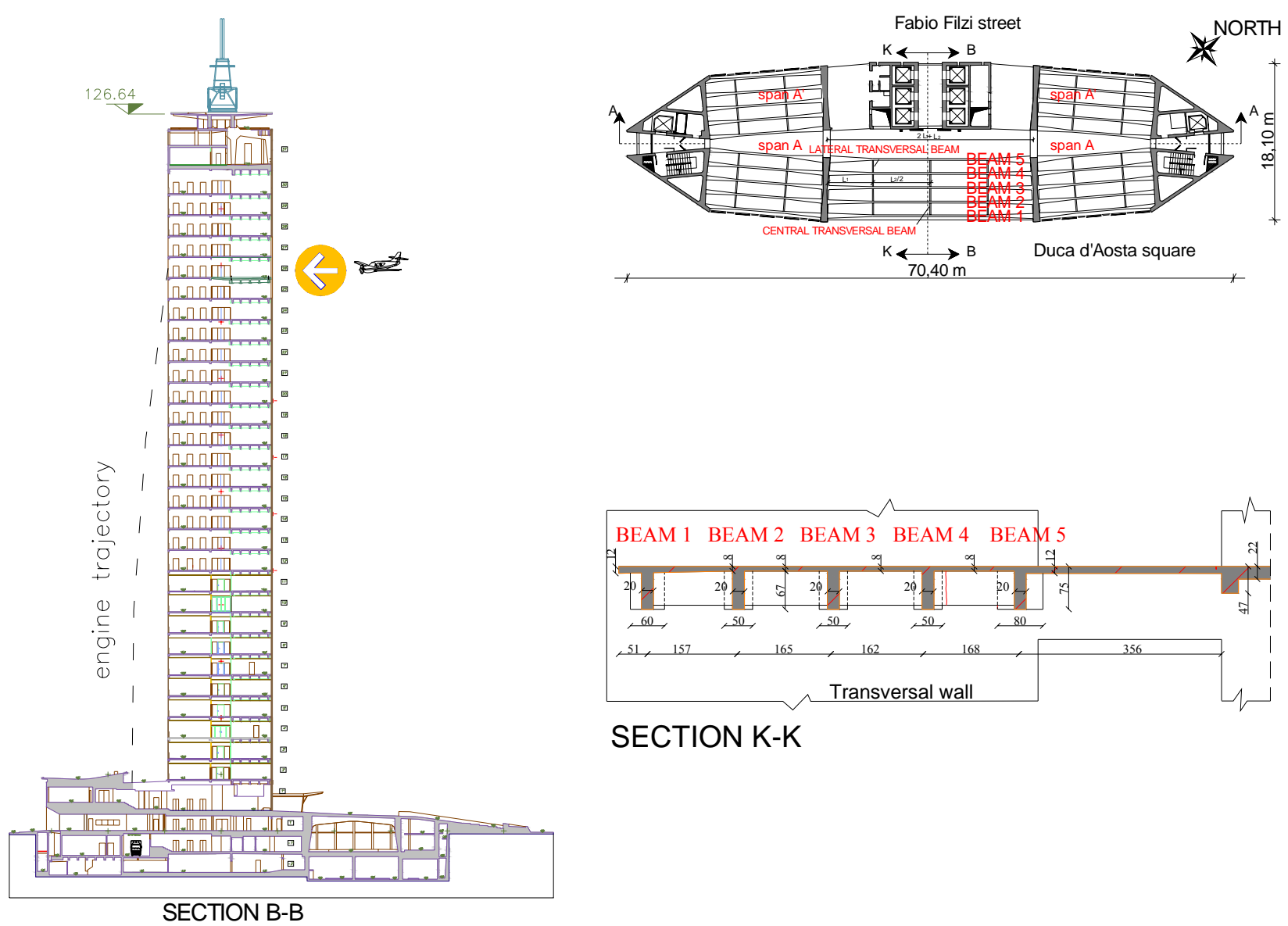

Fig. 1: Longitudinal section (section B-B of Fig. 2: Plant and section of the floor Fig 2)

As the sequel of this paper will show, achievement of this objective was made possible by relying on plastic displacement set up in the opposite direction in relation to the configuration after the explosion.

Moreover, the reasoning was that it should be possible to arrive to a simple analytical model for estimating the forces required for such a forcing process; such an estimation would be necessary in order to make a suitable choice of the jack types to be utilized on the field.

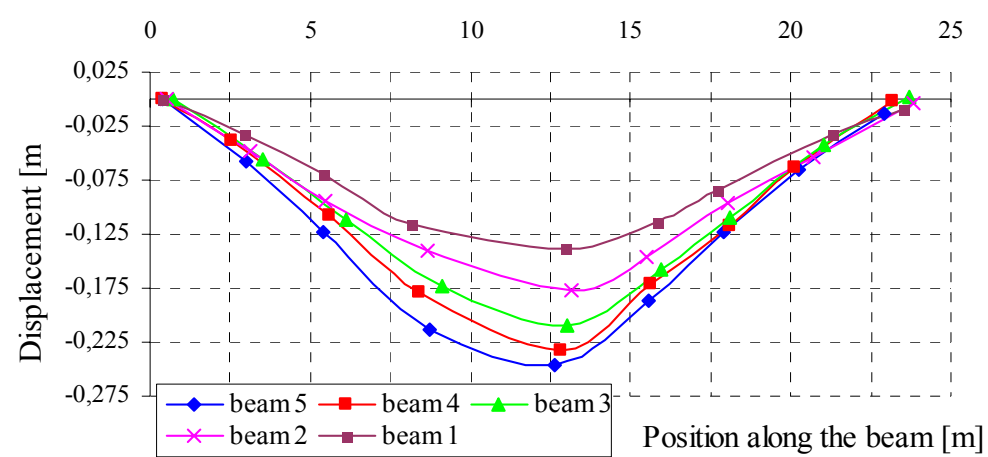

Fig. 3: Residual displacements of the $26^{\text {th }}$ floor beams

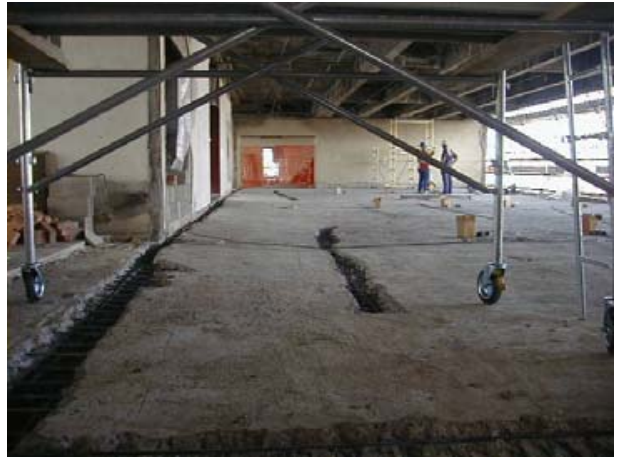

Fig. 4: Yield lines after concrete demolition

\section{Analytical evaluation of the impulsive loading distribution}

The following section will present the results of the analytical evaluation of the impulsive loading distribution which have caused the deformed configuration of the $26^{\text {th }}$ and $27^{\text {th }}$ floors. 
The procedure is similar to that of a back analysis: a black box is developed which transforms forces into displacements: then, knowing the displacement distribution of the floors the loadings are evaluated back.

\subsection{Analytical model: rigid plastic dynamic as a possible tool for evaluating the response of reinforced concrete structures to blast loadings.}

The following figure (Fig. 5) shows a simple model of a generic beam made of N. 3 plastic hinges connected by two rigid elements. The description of the kinematics of the system is expressed in terms of rotation, rotation velocity and rotation acceleration of the plastic hinge and displacement, velocity and acceleration of a point on the rigid links between two plastic hinges.

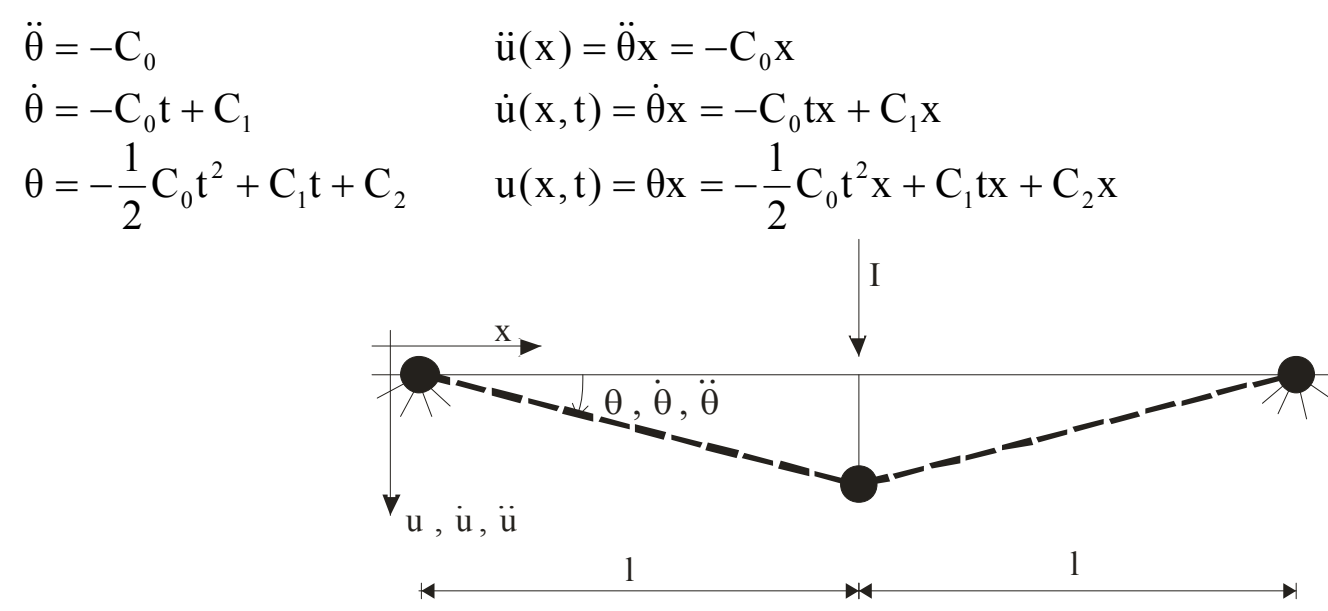

Fig. 5: Plastic hinges model of a generic beam of the deck

\subsubsection{Determination of $\mathrm{C}_{2}$}

$\mathrm{C}_{2}=0$ because $\theta=0$ for $\mathrm{t}=0$

\subsubsection{Determination of $\mathrm{C}_{1}$}

Constant $\mathrm{C}_{1}$ is determined by the initial condition: for $\mathrm{t}=0 \dot{\mathrm{u}}_{0}(\mathrm{x})=\dot{\theta}_{0} \mathrm{x}=\frac{\dot{\mathrm{u}}_{0}}{\mathrm{l}} \mathrm{x}$, then $\mathrm{C}_{1}=\frac{\dot{\mathrm{u}}_{0}}{\mathrm{l}}$

where 1 is the length of the rigid link between two plastic hinges, or $1 / 2$ of the total length of the beam and $\dot{\mathrm{u}}_{0}$ is the initial velocity of the mid span section of the beam.

\subsubsection{Determination of $\dot{\mathrm{u}}_{0}$ as a function of the impulsive loading I}

By calling with A the section area of the beam, with $\rho$ the density and $m$ ' the mass of the beam for unit length, the definition of impulse loading I reads:

$$
\mathrm{I}=2 \int_{0}^{1} \mathrm{~A} \rho \dot{\mathrm{u}}_{0}(\mathrm{x}) \mathrm{dx}=2 \int_{0}^{1} \mathrm{~A} \rho \dot{\theta}_{0} \mathrm{xdx}=\mathrm{m}^{\prime} \mathrm{l}^{2} \dot{\theta}_{0}=\mathrm{m}^{\prime} \mathrm{u}_{0}
$$

2.1.4 Determination of the plastic hinge rotation acceleration $\mathrm{C}_{0}$

Constant $\mathrm{C}_{0}$ is determined by imposing that, during the motion, the sum of kinetic energy $\mathrm{K}$, load potential $\mathrm{U}$, energy dissipated $\mathrm{D}$ is constant, or, in terms of rate quantities:

$\dot{\mathrm{K}}-\dot{\mathrm{W}}+\dot{\mathrm{D}}=0$

where $\dot{U}=-\dot{W}$, i.e. the rate of load potential is equal to minus the rate of the load work. By expressing $\mathrm{K}, \mathrm{W}$ and $\mathrm{D}$ as: 
$\dot{\mathrm{K}}=2 \frac{1}{2} \int_{0}^{1}$ A $2 \dot{\mathrm{u} u ̈ d x} \quad \dot{\mathrm{W}}=2 \int$ A $\rho$ güdx $\quad \dot{\mathrm{D}}=2\left(\mathrm{M}_{\mathrm{L}}^{\mathrm{S}+}+\mathrm{M}_{\mathrm{L}}^{\mathrm{F}-}\right) \dot{\theta}$

where $\mathrm{M}_{\mathrm{L}}^{\mathrm{S}}, \mathrm{M}_{\mathrm{L}}^{\mathrm{F}-}$ are the absolute values of the mid span positive (bottom fibres in tension) and of the fixed end negative (top fibres in tension) ultimate moments (which correspond to the yield of the steel in tension).

By imposing the above equation, after some algebra, the following result is obtained:

$$
\ddot{\theta}=-\frac{6\left(\mathrm{M}_{\mathrm{L}}^{\mathrm{S}+}+\mathrm{M}_{\mathrm{L}}^{\mathrm{F}-}\right)-3 \mathrm{~m}^{\prime} \mathrm{gl} \mathrm{l}^{2}}{2 \mathrm{~m}^{\prime} \mathrm{l}^{3}}
$$

The time $t_{f}$ required to stop the dynamic process is determined by imposing zero velocity, i.e.

$$
\dot{\mathrm{u}}=-\frac{6\left(\mathrm{M}_{\mathrm{L}}^{\mathrm{S}+}+\mathrm{M}_{\mathrm{L}}^{\mathrm{F}-}\right)-3 \mathrm{~m}^{\prime} \mathrm{gl} \mathrm{l}^{2}}{2 \mathrm{~m}^{\prime} 1^{3}} \mathrm{xt}_{\mathrm{f}}+\frac{\dot{\mathrm{u}}_{0}}{1} \mathrm{x}=0
$$

which gives:

$$
\mathrm{t}_{\mathrm{f}}=\frac{2 \mathrm{Il}}{6\left(\mathrm{M}_{\mathrm{L}}^{\mathrm{S}+}+\mathrm{M}_{\mathrm{L}}^{\mathrm{F}-}\right)-3 \mathrm{~m}^{\prime} \mathrm{gl}^{2}}
$$

and, finally, the mid span final displacement (positive if downward) as:

$$
\mathrm{u}_{\mathrm{f}}^{+}=\frac{\mathrm{I}^{2}}{\mathrm{~m}^{\prime}\left[6\left(\mathrm{M}_{\mathrm{L}}^{\mathrm{S}+}+\mathrm{M}_{\mathrm{L}}^{\mathrm{F}-}\right)-3 \mathrm{~m}^{\prime} \mathrm{gl} 1^{2}\right]}
$$

where $\mathrm{m}$ ' is the mass per unit length.

The final displacement at mid span of a beam which has an impulse force in the opposite versus, from the bottom to the top, may be expressed as:

$$
u_{\mathrm{f}}^{-}=-\frac{\mathrm{I}^{2}}{\mathrm{~m}^{\prime}\left[6\left(\mathrm{M}_{\mathrm{L}}^{\mathrm{S}-}+\mathrm{M}_{\mathrm{L}}^{\mathrm{F}+}\right)+3 \mathrm{~m}^{\prime} \mathrm{g} 1^{2}\right]}
$$

Where $\mathrm{M}_{\mathrm{L}}^{\mathrm{S}-}, \mathrm{M}_{\mathrm{L}}^{\mathrm{F}+}$ are the negative ultimate moment at mid span and the positive ultimate moment at fixed end respectively.

\subsubsection{Results}

The analytical model predicts a distribution of impulsive loading as follows: on beam N. 5 an downward impulse of $56 \mathrm{kN} \times \mathrm{s}$ and an upward impulse of $31 \mathrm{kN} \times \mathrm{s}$, on beam N. 4 an downward impulse of $41 \mathrm{kN} \times \mathrm{s}$ and an upward impulse of $28 \mathrm{kN} \times \mathrm{s}$; beam N. 1 a downward impulse of 29 $\mathrm{kN} \times \mathrm{s}$.

\section{Methodological aspects of the realigning phase}

\subsection{Goals of the realigning}

It has been recognized that the first operation to be carried out, before any type of consolidation of the structures, had to be the realigning of the principal beams of the $26^{\text {th }}$ floor. Only after the realigning, in fact, it is conceivable to remove the damaged concrete, substitute those parts of the bars which did suffer inelastic strains especially in compression, to reconstruct the concrete sections with special mortars, and finally to apply a post-tensioning steel system which will increase the safety level of the repaired structure. The designer has requested to perform the realigning with a maximum tolerance on the residual displacement of about 2-3 cm, better if above the horizontal line.

\subsection{Operative procedure for the realigning}

The operative procedure had to employ N. 15 hydraulic jacks (see Fig. 6) positioned in 
correspondence with the intersection of the 5 longitudinal beams with the 3 transversal beams; then other 4 jacks where added in between the previous points, only for beam No. 3 and 5, in order to distribute the loads in a more uniform way, especially for the most loaded beams.

The jacks were placed in contact to bottom face of the beams by means of provisional steel beams fixed to the floor. Close to the jack points some steel tubular props follow the realigning process, by adapting their height, step by step, in order to follow the movements of the beams.

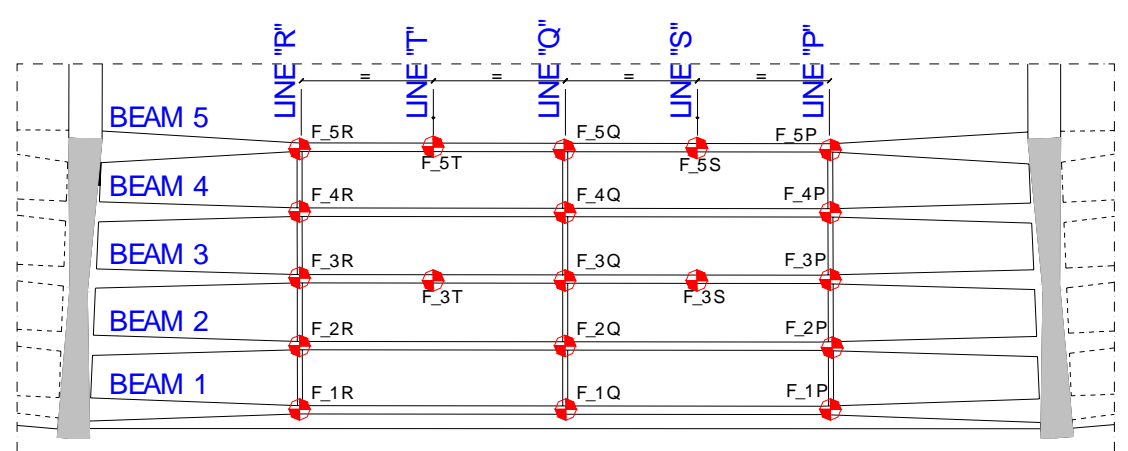

Fig. 6: Hydraulic jacks distribution

The first question, expressed by the laboratory experts, was:

What force was necessary to apply, totally, to the floor in order to obtain the realignment?

And, immediately after, the second question became:

What displacement, upward the horizontal line, would have been necessary to achieve in order to obtain a flat plane after removal of the applied forces?

Again, a simple model, made of three plastic hinge connected by rigid elements, helped in solving the questions.

The idea was that to force the beams up to collapse (in the opposite direction with respect to the dead loads and therefore remaining always in a neutral-stable configuration) and then to move the mid span section of each beam upward with respect to the horizontal line of a displacement equal to the elastic displacement caused by the same 3 point loading forces.

\subsection{Analytical model for the evaluation of the total force to be applied in order to obtain the realigning}

The following Fig. 7 shows the simple model where the notation is the same adopted in the previous paragraph. The applied forces are: N. 3 point loads equal to F/3, representing the action of the hydraulic jacks, and the self weight per unit length denoted with $\mathrm{p}$.

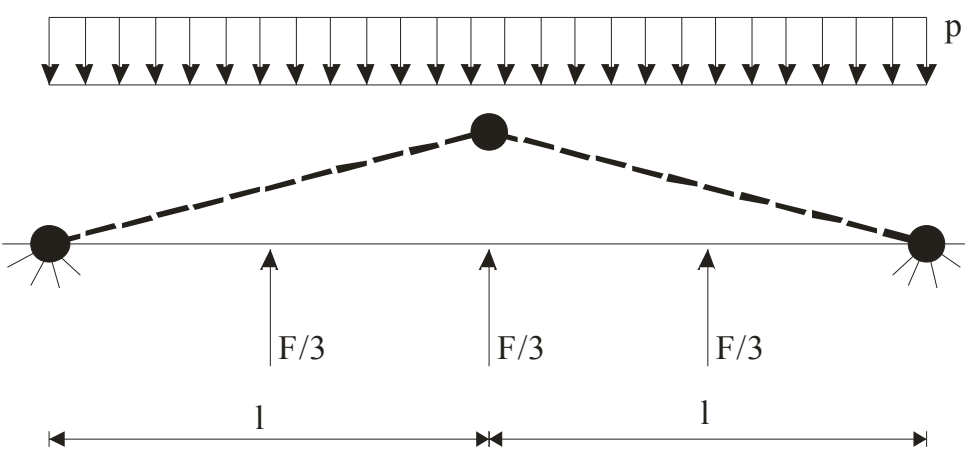

Fig. 7: Model for the realigning process

The limit load $\mathrm{F}_{\mathrm{u}}$ may be expressed as:

$\mathrm{F}_{\mathrm{u}}=\frac{3\left(\mathrm{M}_{\mathrm{L}}^{\mathrm{F}+}+\mathrm{M}_{\mathrm{L}}^{\mathrm{S}-}\right)}{1}+\frac{3}{2} \mathrm{pl}$ 
Results: by applying the above formula to beams $1,2,3,4,5$ and summing the obtained forces, a total force of approximate $2600 \mathrm{kN}$ is obtained. The experimental results proved the goodness of the assumptions.

\subsection{Analytical model for predicting the upward displacement to be reached during the realigning phase}

The displacement, to be reached in the realigning process over the horizontal line, has been evaluated according to the following procedure.

\subsubsection{Evaluation of the displacement at service due to permanent loading}

The model was that of a fixed end beam subjected to uniform distributed load of $10 \mathrm{kN} / \mathrm{m}$; the mid span displacement has been estimated, by means of proof experimental tests, to be around $2 \mathrm{~cm}$. The corresponding average elastic stiffness EJ has been computed equal to $432000 \mathrm{kN} \times \mathrm{m}^{2}$. That average stiffness was in between the un-cracked and fully cracked stiffness.

\subsubsection{Estimate of the elastic stiffness after the explosion and the realigning process}

It was difficult to estimate the degradation of that stiffness due to the explosion and the realigning process; it was important to remark that, in any case, only the critical sections suffered limited damages, suggesting therefore that the average elastic stiffness should have preserved quite well.

It has been considered, by assuming a conservative view point that the actual elastic stiffness was about half the original, i. e. about $200000 \mathrm{kN} \times \mathrm{m}^{2}$.

\subsubsection{Estimate of the displacement up to the horizontal line to be attained during the realigning process of beam No. 5}

By assuming a fixed end beam subjected to three point loads equal to $F / 3$, the elastic displacement at mid span can be expressed as:

$$
\mathrm{f}=\frac{\mathrm{Fl}^{3}}{36 \mathrm{EJ}}=\frac{493 \times(12)^{3}}{36 \times 200000}=0.118 \mathrm{~m}
$$

Therefore the target for beam No. 5 was fixed into $12 \mathrm{~cm}$.

\subsection{Operative realigning procedure}

Forcing operations have been obtained by applying point forces as described at paragraph 3.2.

The load control system (see Figure 8 at right) consisted of an oil distributor which controlled, through suitable valves, the oil flow in each jack. Unfortunately the section of the pistons of the jacks was not uniform, so that it was not possible to apply a monotonic increase of the load of each point load. The sequence of the loading history has been organized so that the final load was subdivided into steps: inside each loading step, single beams have been loaded one after the other starting from No. 5 to finish with No. 1. The loading of each single beam has been obtained, at each loading step, by increasing the lateral loads and keeping the central load constant, and then vice versa, i.e. increasing the central load by keeping the lateral loads constant. Unfortunately it was not possible, by means of force control jacks, to keep constant the force in one jack by increasing the load in an other. This was obvious because the increase of the displacement at one point generally produced an increase of displacement in all other points, after each loading steps the props have been adjusted in order to adapt their length to the new configuration.

The $25^{\text {th }}, 24^{\text {th }}, 23^{\text {rd }}$ and $22^{\text {nd }}$ floors have been stiffened provisionally by pack props in order to accommodate the total force imposed to the $26^{\text {th }}$ floor. The total force was therefore distributed on 4 floors, such that each floor would take no more then the allowable service load. 

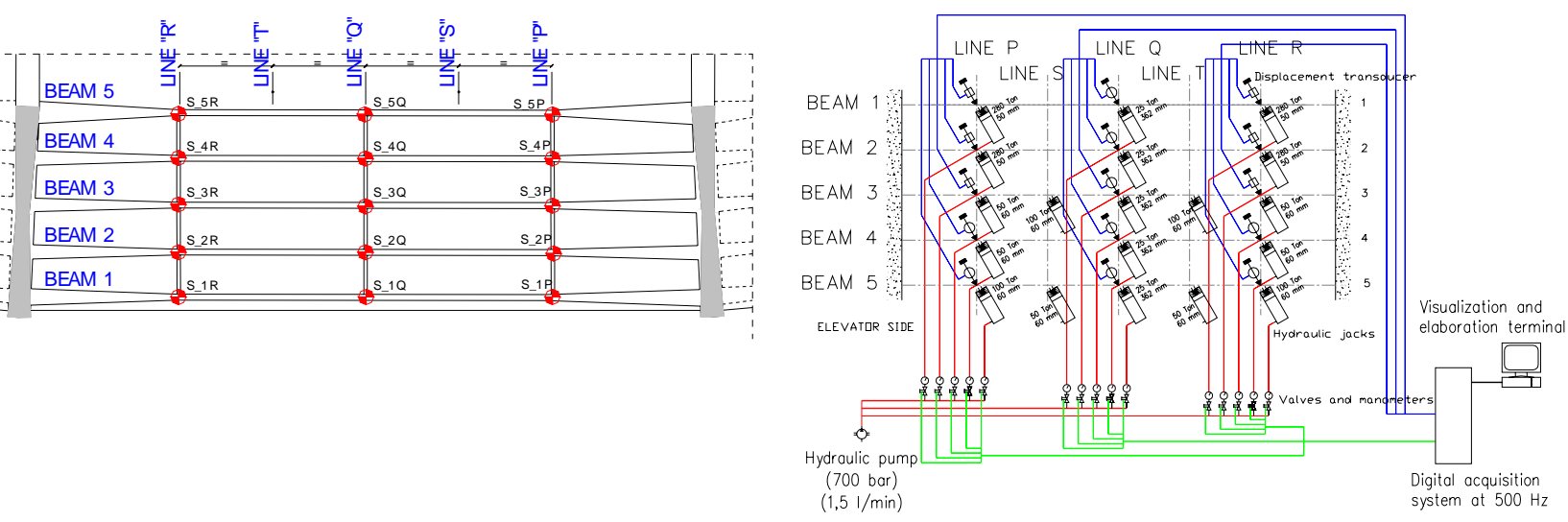

Fig. 8: load (right) and displacement (left) control systems

The displacement monitoring system (see Figure 8 left) was made of No. 15 displacement electrical transducers connected to a digital data acquisition system. The displacement transducers were located in between the $26^{\text {th }}$ and $27^{\text {th }}$ floor, by considering the $27^{\text {th }}$ floor as a fixed reference system.

Total time required for the realigning process was about 30 hours, or 3 working days. The following Figure 9 shows a picture of the hydraulic jacks and props system (left) and the real time displacement diagram (right) during forcing phase.
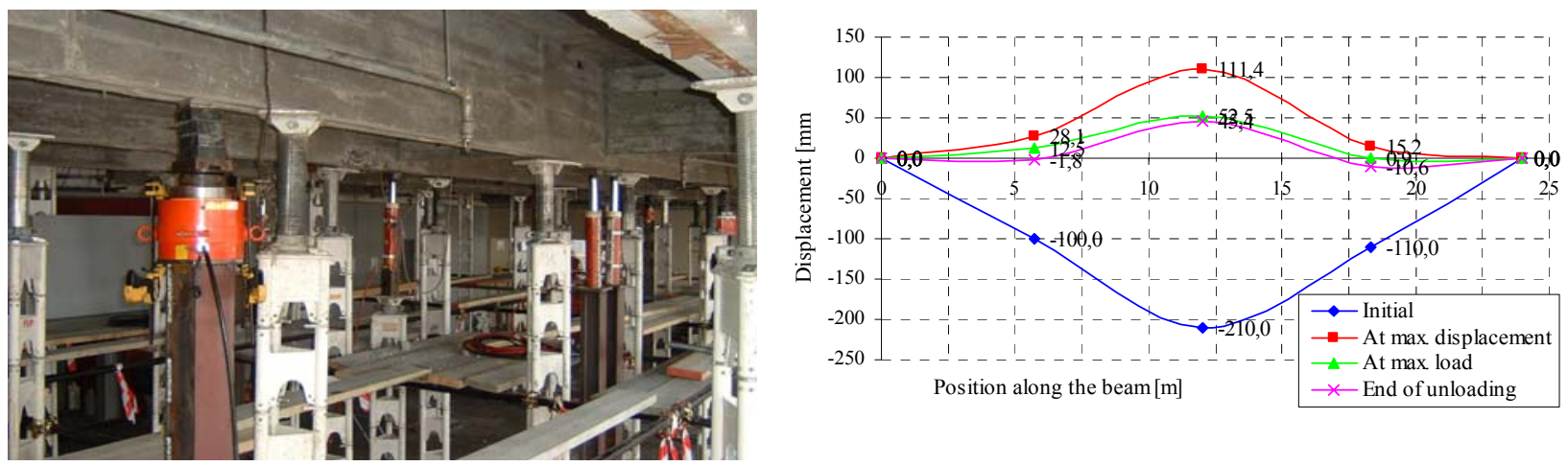

Fig. 9: left, prop and hydraulic jacks at beam No. 3 and, rigth, displacement monitoring during the forcing process

The following Figure 10 (left) shows a picture of the mid span plastic hinge of beam No. 5 during the final stages of the realigning. It is remarkable the instable configuration of the compressed bars. Finally the same Figure 10 (right) shows a picture of the $26^{\text {th }}$ floor at the end of the realigning process.
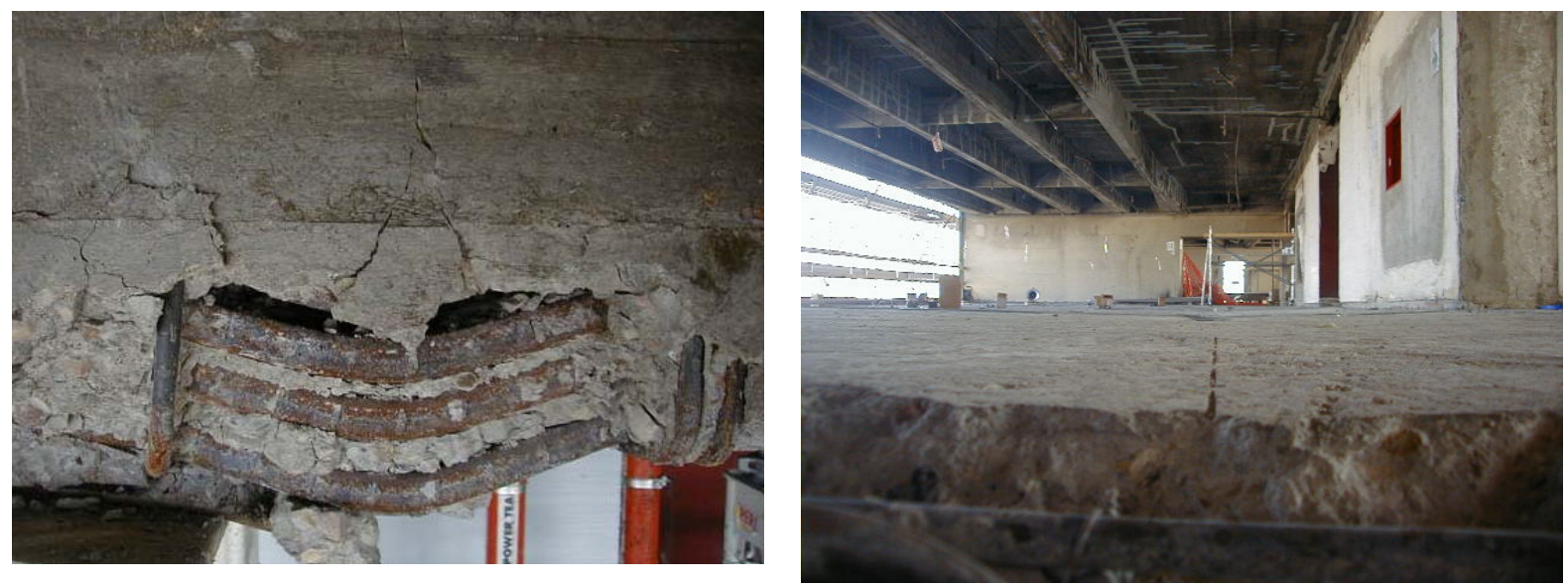

Fig. 10: left, plastic hinge at mid span of beam No. 5 and, right the floor at the end of the realigning process 


\section{Conclusions}

The realigning process has requested, or stimulated, to solve several problems and, among the others, the following are the most significant:

- the evaluation of the impulse forces distribution during the explosion of the aircraft tanks which has probably caused the severe damages of the structures of the $26^{\text {th }}$ and $27^{\text {th }}$ reinforced concrete floors;

- the evaluation of the total force to be applied by No. 15 hydraulic jacks in order to obtain the realigning of the $26^{\text {th }}$ floor;

- the evaluation of the maximum displacement over the horizontal line necessary in order to obtain a flat plane after removal of the forcing jacks action, with a maximum error of $2-3 \mathrm{~cm}$;

- the operative technique able to implement and to control the forces and displacements during the realigning process.

\section{Acknowledgement}

The authors acknowledge the high professional skills of P\&P Consulting Engineers - ISMES-LMC technical staff which has greatly contributed to the success of the entire operation.

\section{Bibliography}

[1] MIGLIACCI A., ACITO M., "La Vicenda del grattacielo Pirelli - il restauro", Mancosu Editore Roma, 2003.

[2] MIGLIACCI A., ACITO M., FRANCHI A., "Il progetto di risanamento delle strutture del grattacielo Pirelli", -Studies and Researches V. 24, Italcementi S.p.A., Bergamo, 2004.

[3] ACITO M., MIGLIACCI A., "Il progetto e la tesatura dei cavi nel risanamento strutturale dell'impalcato del $26^{\circ}$ piano del grattacielo Pirelli", Congresso AICAP - Verona, 2004.

[4] PARK R., PRIESLEY M.J.N., GILL W. D., "Ductility of Square Confined Concrete Columns", Journal of the Structural Division, ASCE Vol.108 n ST4, April1982, pp.929-950.

[5] HODGE P.C. JR., "Plastic Analysis of Structures", Mc Graw Hill, 1959

[6] FRANCHI A., GENNA F., CORRADI L., On the determination of bifurcation and limit points, Journal of Engineering Mechanics, 124 (8),866-874, 1998 